\title{
Manifestaciones purpúricas atípicas por parvovirus B19 en dos miembros de una familia. Caso clínico
}

\author{
María José Martínez G 1,2, Andrea Elgueta $\mathrm{N}^{2}$. \\ A family outbreak of parvovirus B19 \\ atypical exanthemas. \\ Report of two cases
}

Two atypical cases of parvovirus B19 infection occurred consecutively within a family. A 14 year-old patient presented an extended papular-purpuric "gloves and socks" syndrome and two weeks later his mother developed a predominantly unilateral purpuric rash in the limbs with severe malaise. Specific IgM antibodies in the boy and polymerase chain reaction (PCR) and serology in the mother, confirmed parvovirus B19 infection. We emphasize the variable presentation of B19 infection within a family. The importance of etiologic studies in the presence of atypical exanthemas and the utility of PCR in the diagnosis of B19 are undesrscored (Rev Méd Chile 2008; 136: 620-3).

(Key words: Exanthema; Parvovirus; Polymerase chain reaction)

Recibido el 27 de marzo, 2007. Aceptado el 3 de agosto, 2007.

${ }^{1}$ Clínica Las Condes. ${ }^{2}$ Programa de Virología. Instituto de Ciencias Biomédicas (ICBM). Facultad de Medicina. Universidad de Chile. Santiago de Chile.

$\mathrm{P}$ arvovirus B19 (PVB19) fue descubierto por Yvonne Cossart en $1975^{1}$ y se asoció con enfermedad humana a principios de $1980^{2}$. En la actualidad es reconocido como agente causal del eritema infeccioso, artropatías en adultos sanos, hidrops fetal no inmune, crisis aplástica transitoria en pacientes con eritropoyesis aumentada y de anemia persistente en inmunocomprometidos ${ }^{3}$. $\mathrm{Si}$ bien la mayoría de las infecciones por este virus

Correspondencia a: Dra. Mańa José Martínez Galofré. Programa de Virología, Instituto de Ciencias Biomédicas, Facultad de Medicina, Universidad de Chile. Av. Independencia 1027. Santiago. Chile. Teléfono: 562 9786322. Fax: 5629786124. E mail: mmartine@med.uchile.cl son asintomáticas, se ha reportado un amplio espectro de enfermedades con asociación variable a PVB19. Entre ellas, el síndrome pápulo-purpúrico en guante y calcetín (SPPGC); exantema periflexural asimétrico; otros exantemas de tipo morbiliforme, vesiculosos, purpúricos o polimorfos; lívedo reticular generalizado ${ }^{3-5}$ y aún es dudosa su asociación etiológica con enfermedad de Kawasaki6.

PVB19 pertenece a la familia Parvoviridae, género Erythrovirus y es el único agente de este grupo capaz de infectar al hombre. Es un virus pequeño (de 20 a $25 \mathrm{~nm}$ ), de cápsula icosaédrica, genoma ADN de hebra simple y no posee manto viral, lo que le concede una elevada resistencia al calor y solventes ${ }^{6,7}$. Para replicarse requiere células en división activa y que expresen en su 
membrana el antígeno $\mathrm{P}$, por lo que infecta principalmente a los precursores eritroides de la médula ósea y las células hepáticas del feto. Se ha detectado también en células miocárdicas, endoteliales y en precursores de granulocitos, megacariocitos y macrófagos ${ }^{7}$. La transmisión ocurre vía respiratoria, siendo muy frecuente el contagio intrafamiliar y en comunidades cerradas (brotes). También puede transmitirse vía hematógena $\mathrm{y}$ vertical $^{3,6}$. El período de incubación se ha estimado en una a dos semanas, pudiendo extenderse hasta tres ${ }^{7}$. La infección por PVB19 es de distribución mundial y ocurre generalmente en la infancia, alcanzando una seroprevalencia de $50 \%$ a los 15 años y de $90 \%$ en la vida adulta ${ }^{8}$. En Santiago de Chile, se han reportado seroprevalencias de $50 \%$ a $60 \%$ en adultos jóvenes ${ }^{9}$ y de $57 \%$ en donantes de banco de sangre ${ }^{8}$.

Existen escasas publicaciones en la literatura intemacional que demuestren diferentes manifestaciones clínicas de la infección por PVB19 en miembros previamente sanos de una familia ${ }^{10-12}$. Este artículo constituye el primer reporte en nuestro país de presentaciones clínicas diferentes, en dos miembros de un grupo familiar constituido por cuatro personas y seguido en el tiempo por un mes.

Caso clínico 1. Paciente de 14 años de edad, previamente sano. Como antecedentes sólo refería una rinitis alérgica diagnosticada hace 8 años y estar vacunado contra hepatitis A y B en 2003. En

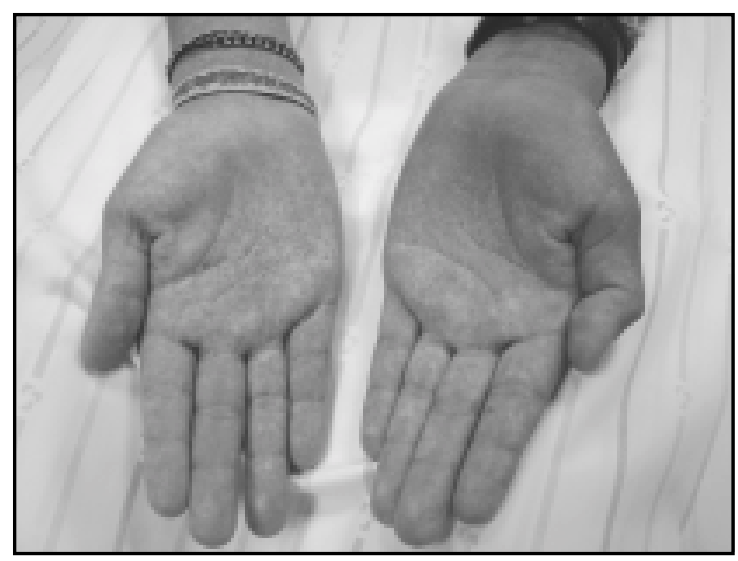

Figura 1. Exantema máculo-papular, púrpura no palpable y edema de ambas manos. mayo de 2006 inició un cuadro caracterizado por eritema y prurito en la zona dorsal y palmar de ambas manos, y edema progresivo de los pies, a lo que se agregó fiebre (hasta $38,9^{\circ} \mathrm{C}$ ) y vómitos. La madre le administró Celestamine ${ }^{\circledR}$ (maleato de dexclorfeniramina $2 \mathrm{mg}$ y betametasona $0,25 \mathrm{mg}$ ) oral cada $6 \mathrm{~h}$ durante dos días, sin embargo las lesiones se extendieron comprometiendo en $72 \mathrm{~h}$ toda la piel de las extremidades y gran parte del tronco. Al quinto día de evolución el paciente consultó, constatándose en buen estado general, afebril, con un exantema máculo-papular y púrpura no palpable en tronco y extremidades, de predominio distal, acompañado de edema de manos y pies (Figuras 1 y 2). No se observaban lesiones en la cara ni en las mucosas. Se diagnosticó un SPPGC extenso, por lo que se indicó reposo relativo, Clorprimetón ${ }^{\circledR}$ (maleato de clorfenamina $4 \mathrm{mg}$ ) oral cada $8 \mathrm{~h}$ y lubricación corporal. Se solicitaron exámenes generales y serología para PVB19. Entre los exámenes destacó un recuento de leucocitos de 4.080 células/ $\mu$ l (basófilos 1\%, eosinófilos 2\%, baciliformes $13 \%$, segmentados $38 \%$, linfocitos $33 \%$, monocitos $12 \%$ e inmunocitos $1 \%$ ) y velocidad de eritrosedimentación (VHS) de $37 \mathrm{~mm} / \mathrm{h}$. No presentó anemia pero se describió una microcitosis normocrómica discreta y ovalocitos escasos. La IgM para PVB19 fue positiva y la IgG negativa. A los diez días de evolución acudió a control, encontrándose completamente asintomático y sin lesiones cutáneas, por lo que fue dado de alta.

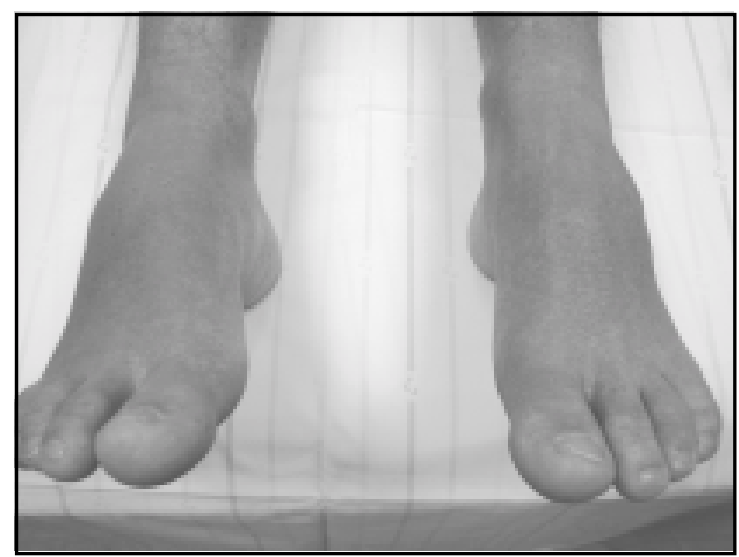

Figura 2. Exantema máculo-papular, púrpura no palpable y edema de ambos pies. 
Caso clínico 2. Paciente mujer de 40 años, madre del caso descrito. Sin antecedentes mórbidos de importancia, usuaria de anticonceptivos orales, además de Clonazepam en forma ocasional. Vacunada contra la hepatitis A y B en 2003. Dos semanas después del SPPGC de su hijo, comenzó con un cuadro de compromiso del estado general (CEG) intenso, mareos y sensación de calofríos, asociado a un exantema en el muslo izquierdo. Se agregó dolor abdominal, náuseas y cefalea holocránea leve. Luego de cuatro días de evolución consultó, observándose un exantema purpúrico no palpable $<4 \mathrm{~mm}$ en la zona proximal de ambos muslos, de predominio izquierdo y compromiso de la región inguinal izquierda. No presentaba lesiones en cara ni mucosas. Se diagnosticó un exantema macular purpúrico pequeño atípico, se solicitaron exámenes generales y estudio serológico para PVB19. En los exámenes destacaba una leucopenia de 3.440 células/ $\mu \mathrm{l}$ y una VHS de 21 $\mathrm{mm} / \mathrm{h}$, además de una ligera elevación de la transaminasas. La serie roja, las plaquetas y el tiempo de protrombina fueron normales. La serología para PVB19 (IgM e IgG) realizada cinco días después del inicio de los síntomas, fue negativa. La paciente evolucionó con mialgias y artralgias sin artritis, por lo que se decide solicitar una reacción en cadena de la polimerasa (PCR) para PVB19 en sangre y repetir la serología. La PCR para PVB19 e IgM específica resultaron positivas a la semana de iniciado el cuadro. Al noveno día de evolución se encontraba asintomática, afebril, y sin lesiones cutáneas, por lo que fue dada de alta.

\section{Discusión}

Presentamos dos casos intrafamiliares de presentación atípica de la infección por PVB19. En el paciente adolescente la infección se presentó como un SPPGC con gran extensión proximal del exantema pero leve repercusión sistémica, mientras que en el caso del adulto, la infección se manifestó con mayor compromiso sistémico y un exantema purpúrico atípico de predominio unilateral con compromiso del pliegue inguinal.

El SPPGC es una enfermedad exantemática cuya etiología más importante es PVB19, aunque también se ha asociado a virus hepatitis $B$ entre otros $^{13,14}$. Afecta especialmente a adultos jóvenes y se caracteriza por edema y eritema de manos y pies, de inicio brusco y progresivo, que no sobrepasa la muñeca ni los tobillos. Generalmente asociado a fiebre y compromiso de mucosas. La presentación clínica puede variar enormemente en cuanto a las características y extensión de las lesiones, y a la presencia de otros síntomas y signos agregados ${ }^{13-17}$. Por esta variabilidad y por la posibilidad de diferentes causas, el estudio etiológico de los casos sospechosos de SPPGC es importante.

La distribución de las lesiones del caso 2 se asemeja al exantema periflexural asimétrico, sin embargo, las lesiones que presentaba no eran máculo-papulares como se describe habitualmente en este cuadro sino purpúricas. En las últimas dos décadas se han descrito casos aislados de diferentes exantemas papulares-purpúricos asociados a la infección por PVB1918, además de manifestaciones extracutáneas y sistémicas ${ }^{3,11,17}$. El compromiso articular (artralgias o artritis) se ha reportado con frecuencia, especialmente en mujeres adultas ${ }^{3,6}$ tal como ocurrió en el caso que presentamos.

El estudio de laboratorio mostró un leve aumento de la VHS, además de leucopenia y aumento de las transaminasas en el caso de la madre, lo que concuerda con lo descrito en las infecciones por PVB19 en inmunocompetentes ${ }^{3}$. El diagnóstico de la infección aguda por PVB19 en inmunocompetentes se realiza mediante la detección de IgM específica. Los niveles de IgM comienzan a elevarse durante la primera semana, son positivos en $85 \%$ a $90 \%$ de los pacientes durante la segunda semana y se mantienen generalmente hasta el tercer mes $^{3,6}$. Sin embargo, existen casos en los cuales no se detecta inicialmente el alza serológica y la presencia del virus sólo es evidente mediante PCR, que tiene la ventaja de detectar niveles bajos de ADN viral en distintos fluidos y tejidos desde la primera semana de infección ${ }^{7}$. Se ha descrito la persistencia de ADN viral por períodos prolongados en suero de pacientes inmunocompetentes, en membrana sinovial y médula ósea, por lo que se ha sugerido no utilizar esta técnica como única herramienta de diagnóstico de infección aguda por PVB196.

La mayor parte de los casos reportados en la literatura de infección intrafamiliar por PVB19, corresponden a crisis transitorias de anemia 0 aplasia medular en familias que padecen trastor- 
nos hematológicos previos ${ }^{19,20}$. En miembros inmunocompetentes de una familia, los cuadros clínicos hasta ahora descritos difieren de nuestros casos. Probablemente la demostración de diferen-

\section{REFERENCIAS}

1. Cossart Ye, Field AM, Cant B, Widdows D. Parvovirus-like particles in human sera. Lancet 1975; 1: 72-3.

2. Pattison JR, Jones SE, Hodgson J, Davis LR, White JM, Stroud CE et al. Parvovirus infections and hypoplastic crisis in sickle cells anaemia. Lancet 1981; 1: 664-5.

3. Young NS, Brown KE. Parvovirus B19. N Engl J Med 2004; 350: 586-97.

4. Tomulic V, Martínez M, Saavedra T, Sazunic I, Morales C. Parvovirus B19, a propósito de un caso de "Enfermedad en guante y calcetín". Rev Chilena Dermatol 2005; 21: 20-3.

5. Guimerá-Martin-Neda F, Fagundo E, Rodríguez F, Cabrera R, Sánchez R, García M et al. Asymmetric periflexural exanthem of childhood: report of two cases with parvovirus B19. J Eur Acad Dermatol Venereol 2006; 20: 461-2.

6. HeEgaARD ED, Brown KE. Human parvovirus B19. Clin Microbiol Rev 2002. 15: 485-505.

7. Anderson L. Human Parvovirus B19. En: Richman D, Whitley R, Hayden F, Ed. Clinical Virology. Editorial Churchill Livingstone Inc, 1997; 613-31.

8. Gaggero A, Rivera J, Calquín E, Larrañaga C, León O, Díaz P et al. Seroprevalencia de anticuerpos IgG contra Parvovirus B19 en donantes de sangre de hospitales de Santiago, Chile. Rev Méd Chile 2007; 135: 443-8.

9. Abarca K, Cohen BJ, Vial PA. Seroprevalence of parvovirus B19 in urban Chilean children and young adults, 1990 and 1996. Epidemiol Infect 2002; 128: 59-62.

10. López-Expósito R, Uriz S, Mairal JA, Quintana M, LEDESMA L, BELA F. Intrafamily infection caused by parvovirus B19: different manifestations according to age. Enferm Infecc Microbiol Clin 1996; 14: 66-7. tes manifestaciones cutáneas por PBV19 estaría relacionada a factores del hospedero como: la edad, diferencias genéticas, de la respuesta inmune u otros que deberán ser determinados.

11. Pereira AC, Barros RA, Do Nascimento JP, De Oliveira SA. Two family members with a syndrome of headache and rash caused by human parvovirus B19. Braz J Infect Dis 2001; 5: 37-9.

12. Leahy ST, Marshman G. Variable presentation of Parvovirus B19 in a family. Australas J Dermatol 1998; 39: 112-5.

13. Alfadiey A, Aljubran A, Hainau B, Alhokail A. Papular-purpuric "gloves and socks" syndrome in a mother and daughter. J Am Acad Dermatol 2003; 48: 941-4.

14. Passoni LF, Ribeiro SR, Giordani ML, Menezes JA, NASCIMENTO JP. Papular-purpuric "gloves and socks" syndrome due to parvovirus B19: report of a case with unusual features. Rev Inst Med Trop Sao Paulo 2001; 43: 167-70.

15. Petter G, Rytter M, Haustein UF. Juvenile papularpurpuric gloves and socks syndrome. J Eur Acad Dermatol Venereol 2001; 15: 340-2.

16. Eijnden SV, Carlier F, Van Beers D, Dangoisse C, De LAET C. Gloves and socks lymphangitis associated with acute parvovirus B19 infection. Pediatr Dermatol 2003; 20: 184-6.

17. Loukeris D, Serelis J, Aroni K, Tsakris A, Voulgarelis M. Simultaneous occurrence of pure red cell aplasia and papular-purpuric "gloves and socks" syndrome in parvovirus B19 infection. J Eur Acad Dermatol Venereol 2005; 19: 373-6.

18. Mc NeEIY M, Friedman J, Pope E. Generalized petechial enuption induced by parvovirus B19 infection. J Am Acad Dermatol 2005; 52 (5 Suppl 1): S109-13.

19. SKinNIDER LF, MCSheFrrey BJ, Sheridan D, DeneER H. Congenital spherocytic hemolytic anemia in a family presenting with transient red cell aplasia from parvovirus B19 infection. Am J Hematol 1998; 58: 341-2.

20. Granel B, Serratrice J, Rey J, David M, Pache X, BERNIT E ET AL. Acute transitory intrafamilial erythroblastopenia and hereditary spherocytosis: role of parvovirus B19. Rev Med Interne 2001; 22: 664-7 